\title{
The Treatment in a Child Guidance Clinic of Emotionally Disturbed Children Showing Speech Defects
}

\section{By Yvoune Blake Ph.D}

When a child is referred to a Child Guidance Clinic for a speech defect, the preliminary investigation should be thorough enough to indicate whether the trouble is essentially mechanical (i.e. due to wrong learning habits or to incorrect speech and breathing habits), organic (i.e. a physical defect or deformity affecting either the speech directly or the hearing of sounds) or psychological. Obviously. psychotherapy would be essential in the latter cases (if the symptom is serious enough to merit treatment), whereas speech therapy and/or physical help would be necessary for the others.

For the purposes of clear argument, it is helpful to assume that the child with organic or mechanical speech defects is psychiatrically healthy and that the psychiatrically ill child can spontaneously correct his speech defects after the emotional disturbance has been dealt with. Although this is very often not true, it is a justifiable simplification to make just now.

The psychotherapist is thus not a symptom remover; he recognizes the symptoms as an S.O.S. call that justifies a full investigation of the history of the child's emotional development, relative to the environment and to the culture. Treatment is directed towards relieving the child of the need to send out the S.O.S.

The psychotherapist interested in the dynamics of interpersonal relationships and in dynamic psychology generally, tolerates the symptom and tries to make sense out of it, and to understand the role it plays in the developing human personality.

I do not wish to imply that clinics where the avowed aim is to remove the symptom have no value. Mothers and children are grateful; and there is nothing to be said against such clinics except that they side-track the whole issue of etiology, of speech defects as a symptom that means something, as an expression of persisting infantile conflict that has value in the economy of the child. In most cases, cure of the symptom does no harm and when a cure could do harm, the child usually manages through unconscious processes either to resist cure or to adopt an alternative S.O.S. sign one that may produce transfer to another type of clinic.

Often the symptom is easily seen to be quite a subsidiary phenomenon, a little bit of a huge problem of a human being engaged in trying to develop to maturity in spite of handicaps.

It will thus be clear that from the psychotherapist's point of view, it is not initially of major significance whether the child shows through a speech defect or through some other symptom that he is emotionally disturbed, anxious and in need of help. This does not mean that during the course of treatment (often even during the first session) the child will not show why the symptom shown is the particular one of a speech defect rather than some other difficulty; but it does mean that treatment is highly individualized whether the child shows a speech difficulty or some other problem. Children who are showing speech defects for emotional reasons cannot be grouped together any more significantly than those showing other disturbances - there may be an emphasis on oral difficulties in such children - particular concern say about oral aggression: biting, eating up, greed - but then again the underlying anxiety or need may be only indirectly concerned with speech or the mouth and more directly with relationships - especially interfamily relationships.

I would like to illustrate these points by giving a short account of three cases that were seen by me - all referred for speech defects. Two of the children were referred for stammering while the third child was described as "talking indistinctly, using jargon and refusing to co-operate with efforts to correct her speech defect."

CASE 1 Billy, aged eight, was one of two boys in a good family. His elder brother (three years older than Billy) was a straight-forward personality from the beginning and was doing 
well at school and presented no problem. Billy had had a difficult birth, was not breast-fed after the first ten days and had been a restless, difficult baby from the start. He was even now less capable of taking or tolerating frustration. and was described as generally tensed and highly strung. The mother recognized the stammer for which he was referred as "a nervous symptom." At school, Billy was thought to be intelligent but restless and his concentration was poor. It seemed from this history that Billy's stammer could be associated with the difficulties evident even in infancy; the tense restless attitude had shown itself from very early on and from the mother's description could initially have been associated with the discomfort experienced in the feeding situation, which would tend to confuse the child and stimulate his aggression.

Billy came very readily to the playroom. He smiled at me and immediately started putting out the small toy figures and animals without waiting for any explanation or introduction. He remarked, with only the trace of a stammer, that he liked coming to the clinic. I suggested that perhaps he did not feel quite sure about coming and felt that I expected him to like it, even though he could not even know at this stage whether I was a likeable person or not.

He looked rather surprised and then said with great difficulty and a noticeable blocking in his speech that he had been to two other clinics and "they were no good." I took up with him the fact that he obviously then, far from liking to come here, seriously doubted whether I'd be any good. I explained that I was not concerned with his speech as such, but that 1 hoped that we could together try to find out what worried him and what interfered with his ability to express himself freely. I pointed out that the toys, the art materials, and everything else in the room could be used freely by him in any way he chose. He started to build a fort, which was filled with wild animals. He said that they were all so fierce that if I was able to see inside the fort I'd run away. He brought the toy gorilla right up to my face saying "Look they bite, grrrrr!" He put the toy into his mouth, bared his teeth, and with the toy still held in his mouth threatened me wih his "grrrr" sounds. I suggested that he was showing me that the fort was himself, that the wild animals were, in fact, inside HIM, and that he felt that being so full of wild dangerous animal feelings, he had to keep me out for my own protection and keep the wildness inside himself - no wonder it was difficult for him to let out his speech freely because, if he spoke freely the wild animals may come out with the words. "And eat you up," he added. This pre-occupa- tion of Billy's with his "inside", effectively interfered with his outside activities; his continual efforts to deal with and control his "wild feelings" made it impossible for him to concentrate on anything else and his restlessness was associated with his efforts "to keep the animals down". These animals were located in his abdomen and there were many rituals and fantasies associated with placating them, trying to tame them, out-witting them and generally preventing them from destroying him and those he loved. As Billy gradually worked through his anxieties and realized that his aggression could be used and expressed indirectly (and that even expressing it openly and directly occasionally did not cause complete destruction and over-whelming chaos in the world around him), he was able to integrate his personality more successfully and to accept his aggressive impulses as part of himself. The speech difficulties cleared up without the need for speech therapy; and after about fifteen months of weekly therapy sessions, Billy had changed from a confused, disorganized personality who was seriously threatened and disturbed by his difficulties, into a boy who coped very satisfactorily and without undue tension or strain with both his internal and external "worlds".

CASE 2 Peter, aged 10. Peter was the youngest of four boys. He had had an uneventful infancy, had been a "good" baby and had presented no problems until his fourth year when he developed a stammer. The mother felt that he really was still no problem but the father was very concerned about it, and evidently had been since the stammer first started. As the boy appeared so normal, he had been taken on for speech therapy soon after starting school - he attended a speech clinic for about 18 months and then had speech training at school. These latter sessions were still continuing when he finally came to a Child Guidance no blocking of speech but simply an audible Clinic, but the stammer persisted. There was stammer.

During the first few sessions, Peter spent most of his time drawing - the drawings represented "patterns" he had done at school and, in fact, revealed very little beyond the fact that he was not wanting to go into his problem. When this was pointed out to him and it was suggested that he perhaps wanted and needed the stammer and that giving it up represented a bigger threat to him than coping with the difficulties it caused him, he denied this strongly and assured me (as he had assured his father and his teachers) that he "would do anything to be cured". I asked him what, for example. was he willing to do. He thought for a while 
and then said he would even be willing to let his brother (two years older than himself the other two boys were 16 and 18 years respectively and not really important in his life, especially as they were away at boarding school) have his white mice. This led to a discussion of his pets, which the father had given him in the hope that the distraction would help him and cure the stammer. It became obvious that he received many gifts, a considerable amount of attention and enjoyed quite a few privileges from his father - all in the hope of "curing the stammer". The significance of his stammer now became more obvious and also his need not to give it up. As the fourth boy he evidently felt unable to compete directly with his brothers for his father's attention. The stammer was solving this difficulty and bringing him more attention and more material benefits than his brothers enjoyed. At the same time it did cause him considerable suffering and inconvenience, so that he did not have to feel guilty over his need to receive more than his brothers. It was necessary in this case to clarify also to the boy's father how his concern had in a sense encouraged the boy's symptom which seemed to have started as a "normal" speech difficulty of a three year old. As the youngest child, Peter had early on felt the need to compete with his brothers and had shown an over-eagerness to express himself in speech and to make his wants known; and the stammer developed into a problem only when the father became over-anxious about it. The father's concern transformed a temporary and very common difficulty into a chronic symptom. This symptom disappeared only when Peter could prove to himself, with his father's cooperation, that he could have the attention, love and support he needed without clinging to his symptom.

CASE 3 Maisie aged 5. Maisie was the elder of two children - her brother being 20 months younger. The mother felt Maisie had developed normally in most respects, but had never learnt to talk properly. Her developmental quotient and her I.Q. were above average and, except for her speech she was coping well. She was not "babyish" in other ways. She simply refused to speak clearly, and if her parents pretended not to understand her demands, unless verbally expressed, she screamed or refused her food. It became evident that to the mother, the most significant factor was the child's refusal of food and not the speech. To the child it was neither food nor the speech which mattered most but her feeling of having been pushed out by her mother when her brother was born. The mother remembered only later on during treatment that Maisie had been bottle fed until the baby was born, and had been abruptly weaned because the mother could not "have two babies" at the same time. Maisie deeply resented the depriva. tion, she resented the attention the brother reccived and expressed her hostility orally by refusing to "grow up" in this particular way.

From these three examples it will be clear that the speech defect was in each case connected with the child's inter-personal relationships. It was only as he was able to sort these out that the need for the symptom disappeared, and development could proceed normally. I do see the point of view of the person, who not being concerned specifically with dynamic psychology, must ignore the meaning of symptoms and must try to cure them. But I do ask these specialists to give the psychotherapist credit for his point of view. The two disciplines should produce different kinds of child-specialists, each with a healthy respect for the other. The emotionally disturbed child needs treatment, which is geared to his specific needs, and which will reveal the meaning of the symptom - be it a speech defect or other difficulty in the make-up of the child. The symptom is usually an organisation of extreme complexity, one that is produced and maintained because of its value to the developing human personality. The child needs the symptom because of some hitch in emotional development. The psychotherapist is thus concerned with the satisfactory development of the child rather than with the symptom as such.

\section{BOOKBINDING \\ R. KORYTOWSKI}

1 Mylin Court, 24 Belt Street. Doornfontein.

Telephone 44-9602

Four reasons why you should have your Books, Magazines and Thesis bound by us:

1) Modern Linen in 30 colours.

Leather with beautiful grains

2) First class craftsmanship

Guarantee for unbreakable binding

3) QUICK delivery

4) WELL KNOWN FOR REASONABLE PRICES. 